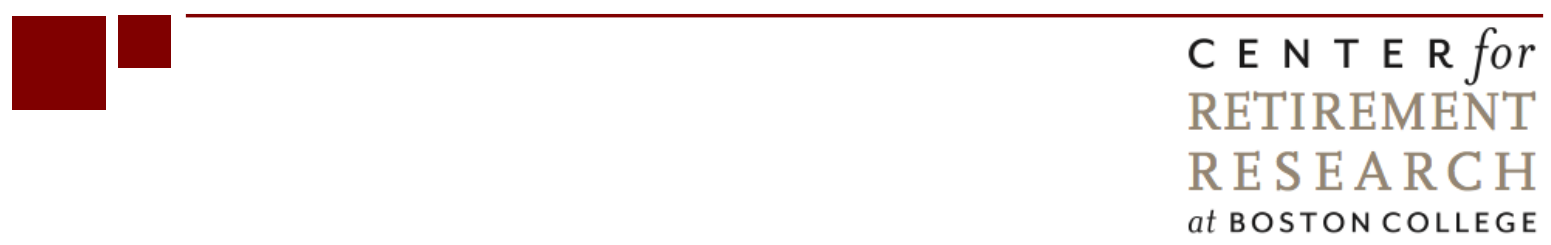

\title{
PRESCRIPTION DRUG INSURANCE COVERAGE, DRUG UTILIZATION, AND COST-RELATED NON-ADHERENCE: EVIDENCE FROM THE MEDICARE PART D EXPANSION
}

\author{
Gary V. Engelhardt \\ CRR WP 2011-19 \\ Date Released: November 2011 \\ Date Submitted: October 2011
Center for Retirement Research at Boston College
Hovey House
140 Commonwealth Avenue
Chestnut Hill, MA 02467
Tel: 617-552-1762 Fax: 617-552-0191
http://crr.bc.edu

Gary V. Engelhardt is a professor of economics at Syracuse University. The research reported here was performed pursuant to a grant from the U.S. Social Security Administration (SSA) funded as part of the Retirement Research Consortium (RRC). The opinions and conclusion expressed are solely those of the author and do not represent the opinions or policy of SSA, any agency of the federal government, the RRC, Syracuse University, or Boston College.

(C) 2011, Gary V. Engelhardt. All rights reserved. Short sections of text, not to exceed two paragraphs, may be quoted without explicit permission provided that full credit, including (C) notice, is given to the source. 


\title{
About the Center for Retirement Research
}

The Center for Retirement Research at Boston College, part of a consortium that includes parallel centers at the University of Michigan and the National Bureau of Economic Research, was established in 1998 through a grant from the Social Security Administration. The Center's mission is to produce first-class research and forge a strong link between the academic community and decision-makers in the public and private sectors around an issue of critical importance to the nation's future. To achieve this mission, the Center sponsors a wide variety of research projects, transmits new findings to a broad audience, trains new scholars, and broadens access to valuable data sources.

\author{
Center for Retirement Research at Boston College \\ Hovey House \\ 140 Commonwealth Avenue \\ Chestnut Hill, MA 02467 \\ phone: 617-552-1762 fax: 617-552-0191 \\ e-mail: crr@bc.edu \\ crr.bc.edu
}

\section{Affiliated Institutions:}

The Brookings Institution Massachusetts Institute of Technology

Syracuse University

Urban Institute 


\begin{abstract}
This paper uses the substantial increase in prescription drug insurance coverage from the adoption of Part D to generate new estimates the impact of coverage on drug utilization and costrelated non-adherence. The analysis uses detailed panel data on the elderly before and after the implementation of Part D drawn from the 2005 and 2007 Prescription Drug Study (PDS), administered as a supplement to the Health and Retirement Study (HRS), a large nationally representative survey of Americans aged 50 and older. Fixed-effect estimates suggest that gaining coverage results in a 15 percent increase in utilization. These results are consistent with the lower end of estimates in the literature. Gaining coverage also is associated with a 20-50 percent reduction in the incidence of cost-related non-adherence. However, even among the uninsured, only a relatively small proportion of drugs (12 percent) are associated with episodes of cost-related non-adherence. So, these large reductions apply to a small slice of all drugs.
\end{abstract}


The impact of prescription drug insurance coverage on drug utilization has been an important topic in the last fifteen years in health economics and health research, both leading up to and after the implementation of Medicare Part D. A key policy concern, and indeed motive for expansions of coverage, is that the uninsured under-consume drugs because of financial constraints, with the primary avenue being cost-related non-adherence in drug regimens. Furthermore, such non-adherence has direct adverse health consequences (Sokol et al., 2005; Heisler et al., 2008). If true, then a key tradeoff in the design of optimal prescription coverage is the balance between the health and financial benefits of reductions in cost-related non-adherence (Madden et al., 2008) and excessive utilization via moral hazard (Pauly, 2004). ${ }^{1}$

Unfortunately, empirical analysis of the impact of insurance coverage on utilization faces two important challenges. First, the presence of unobserved heterogeneity in the demand for prescription drugs may bias estimated impacts on utilization. For example, if those with a high demand for prescription medications also are more likely to have coverage, then standard estimates of the impact of coverage on utilization will be biased upward. Second, as emphasized by Pauly (2004), it is sometimes difficult to interpret (even unbiased) estimates. On the one hand, the finding of a small impact of coverage on utilization may suggest a small role for moral hazard. On the other hand, a small impact may suggest that the particular form of insurance is not very effective in ameliorating the effect of financial constraints. In practice, it can be difficult to separate these effects.

This paper uses the substantial increase in prescription drug coverage for the elderly that resulted from the adoption of Part D to generate new estimates the impact of prescription drug

\footnotetext{
${ }^{1}$ Of course, more broadly this tradeoff would include the social value of all health and consumption-smoothing benefits vs. the costs of adverse selection and welfare diminishing moral hazard. To the extent price exceeds marginal cost for some pharmaceuticals, some moral hazard may be welfare improving. These broader issues are not examined here.
} 
insurance coverage on drug utilization and cost-related non-adherence. The analysis uses detailed data on a strongly balanced panel of those 65 and older (the "elderly" as defined for this study), observed before and after the implementation of Part D in 2006. The data are drawn from the 2005 and 2007 Prescription Drug Study (PDS), administered as a supplement to the Health and Retirement Study (HRS), a large nationally representative survey of Americans aged 50 and older. These rich survey data contain information on prescription drug insurance coverage, utilization, as well as drug-level information from a roster of prescribed medicines. ${ }^{2}$

There are two main innovations. First, the PDS panel data allow for the use of fixedeffect estimators to obtain consistent estimates of the impact of coverage in the presence of timeinvariant unobserved heterogeneity in the demand for prescription drugs. Second, the PDS asked separate sets of questions on drug utilization, vintages, and cost-related non-adherence that, in principle, allow for a disentangling of the impact of insurance on utilization from that on the relaxation of financial constraints.

Using the PDS data, the passage of Part D was associated with a substantial increase in prescription drug coverage from public sources and a decrease in prescription drug coverage from private sources. The fixed-effect estimates suggest crowd-out of $73 \%$ and that, overall, the expansion of Part D raised prescription drug insurance coverage for the elderly by 10 percentage points. These results are remarkably consistent with the findings of Engelhardt and Gruber (2011), who developed a different identification strategy based on instrumental variable estimation and data from the Medical Expenditure Panel Survey (MEPS).

This temporal increase in coverage then is used to identify the impact of coverage on utilization. In particular, the fixed-effect estimates indicate that gaining coverage results in a

\footnotetext{
${ }^{2}$ The 2007 wave of the PDS was released in March, 2011. To the best of my knowledge, this is the first paper to use the PDS panel data.
} 
$15 \%$ increase in utilization, as measured by the number of prescription drugs taken. These results are consistent with a number of older studies on the impact of insurance coverage on utilization done prior to the expansion of Part D, but smaller than effects implied by recent reduced-form analyses of the impact of Part D eligibility on utilization.

Using a variety of measures, including the frequency of unfilled, skipped, or stopped prescription regimens due to cost-related issues, gaining coverage is associated with large reductions (20-50\%) in the incidence of cost-related non-adherence. However, even among the uninsured, only a relatively small proportion of drugs (12\%) are associated with episodes of costrelated non-adherence. So, these large reductions apply to a small slice of all drugs. Furthermore, the impact of gaining insurance on non-adherence is concentrated on "old” drugs, those the individual reports having taken for more than two years. New prescriptions are not differentially less likely to be associated with episodes of non-adherence. Finally, there is no impact of gaining insurance on reports of side effects, a direct health outcome, and the (individual-assessed) importance of drugs to overall health.

The paper is organized as follows. The next section discusses the previous literature. Section II outlines the empirical strategy, the Medicare Part D expansion, and the PDS data. Section III shows the impact of Part D on insurance coverage. Section IV gives the results on utilization. Sections V and VI discuss the findings on the incidence of cost-related nonadherence and side effects, respectively. The paper concludes with a discussion of the implications of the estimates for moral hazard and outlines some important caveats. 


\section{Part I: Previous Literature}

Existing studies on utilization can be split roughly into two sets. The first consists of older studies done prior to the introduction of Part D. They attempted to directly estimate the impact of prescription drug coverage on utilization, and include Lillard et al. (1999), Yang et al. (2008), and Khan and Kaestner (2009), among others. Using a variety of data sources and methods, these studies suggested that gaining drug coverage was associated with an increase of $4-12 \%$ in drug utilization.

The second consists of studies of the impact of Part D on utilization. These examined the reduced-form relationship between Part D eligibility and utilization. For example, Ketcham and Simon (2008), Yin et al. (2008), and Lichtenberg and Sun (2007) found increases in utilization of 4.7\%, 5\%, and 13\%, respectively. Dividing these estimates by the impact of Part D on overall coverage (from any source) expresses these estimates on the same terms as the older studies. ${ }^{3}$ If Part D raised overall coverage by 20\% (Zhang et al., 2009), then the estimates of Ketcham and Simon (2008), Yin et al. (2008), and Lichtenberg and Sun (2007) imply that the impacts of coverage on utilization of 25-65\%, respectively. Alternatively, if Part D raised overall coverage by 10\% (Engelhardt and Gruber, 2011), then these estimates imply that the impacts of coverage on utilization of $50-130 \%$, respectively. Either way, the recent estimates based on the Part D expansion suggest utilization effects from drug coverage as much as an order of magnitude larger than older studies.

Two influential studies suggest that reducing cost-related non-adherence to drug regimens has substantive impacts on health and medical spending. Heisler et al. (2004) examined the impact of cost-related non-adherence on a variety of self-reported health measures

\footnotetext{
${ }^{3}$ Essentially, this is essentially the same as dividing the reduced-form by the take-up rate to get the implied IV estimate.
} 
for older Americans in the HRS in the early and mid-1990s. They found that those who restricted the use of prescription medications because of cost experienced subsequent worse health, especially for those diagnosed with cardiovascular disease and depression. Using data from 1997-9 on beneficiaries under age 65 from a single large employer, Sokol et al. (2005) found that reductions in cost-related non-adherence were associated with reductions in other medical costs for diabetes, hypercholesterolemia, and hypertension.

A series of more recent studies have examined the impact of Part D on the incidence of cost-related non-adherence. Madden et al. (2008) used temporal variation (before vs. after Part D) for all elderly and data from the Medicare Current Beneficiary Survey (MCBS). ${ }^{4}$ Their reduced-form estimates suggest a 15\% decline in cost-related non-adherence for all elderly. Dividing this estimate by impacts of Part D on overall coverage of 20\% (Zhang et al., 2009) and 10\% (Engelhardt and Gruber, 2011) implies a 75-150\% reduction in cost-related non-adherence for those who gained insurance coverage from the Part D expansion. Kennedy et al. (2011) also used MCBS data and temporal variation for the elderly, and found a 70\% reduction in costrelated non-adherence for those who gained drug coverage under Part D.

Overall, the evidence to date implies very large increases in utilization and declines in cost-related non-adherence associated with the expansion of Part D. Why the estimates, in particular, for utilization, differ so much from the older studies is an open question. ${ }^{5}$

\footnotetext{
${ }^{4}$ Zivin et al. (2009) used the same methods and data as Madden et al. (2008), but limited the analysis to cost-related non-adherence among those elderly with depression. Zhang et al. (2010) used a different measure of nonadherence - they defined good adherence as a medication possession ratio of greater than 0.8 — and found a 13.4 percentage-point reduction in non-adherence for older individuals with drug coverage through Medicare Advantage plans, concentrated among those with hyperlipidemia, diabetes, and hypertension.

${ }^{5}$ Ketcham and Simon (2008) discussed numerous ways in which differing data and methods may generate substantial variation in estimated impacts from Part D.
} 


\section{Part II: Empirical Strategy and Data}

Let $i$ and $t$ index the individual and time, respectively. Then the following specification is used to examine the impact of prescription drug coverage on drug utilization:

$$
Y_{i t}=\delta+\theta D_{i t}^{\text {AnyCoverage }}+\mathbf{\varsigma} \boldsymbol{\kappa}_{i t}+u_{i t}
$$

where $Y$ is a dependent variable that measures utilization, and $\boldsymbol{\kappa}$ is a vector of control variables. The error term, $u$, is modeled as

$$
u_{i t}=\gamma_{t}+\eta_{i}+v_{i t} \text {, }
$$

where $\gamma$ is a time effect, $\eta$ is unobserved heterogeneity in the demand for prescription drugs, and $v$ is white noise. The focal explanatory variable is $D^{\text {AnyCoverage }}$, which takes on a value of one if the individual had prescription drug coverage from any source and zero otherwise. The primary objective is to get consistent estimates of $\theta$, which measures the impact of coverage on utilization. A fundamental challenge is that coverage may be correlated with the unobserved heterogeneity, rendering standard estimators, such as Ordinary Least Squares (OLS), biased and inconsistent. The approach taken here is to use a panel fixed-effect estimator to obtain consistent estimates of $\theta$. This requires panel data on coverage and utilization, as well as substantive temporal variation in coverage that varies across individuals in order to identify the estimate of $\theta$. The source used below is that generated by the implementation of Medicare Part D.

Medicare provides universal health insurance coverage to those age 65 and older, as well as to those on the federal disability insurance (DI) program. The original program, adopted in 1965, covered most medical needs for the elderly and disabled, including hospital and doctor costs. However, it excluded coverage for prescription drugs, which have become increasingly important over time in the treatment of common illnesses among the elderly. 
Beginning in 2006, the federal government began to offer prescription drug insurance coverage to the elderly under Medicare Part D. This new Medicare benefit is delivered by private insurers under contract with the government. Beneficiaries can choose from three types of insurance plans for coverage of their drug expenditures: stand-alone plans, called Medicare Prescription Drug Plans (PDP), that just offer prescription drug benefits; Medicare Advantage (MA) plans, which are plans that provide all Medicare benefits (including prescription drugs) such as HMO, PPO, or private FFS plans; or, beneficiaries could retain their current employer/union plan, as long as it is at least as generous as (i.e., actuarially equivalent to) the standard Part D plan.

Enrollment in Part D plans was voluntary for Medicare-eligible citizens, although Medicare recipients not signed up by May 15, 2006, were subject to a financial penalty if they eventually joined the program. One group, however, was automatically enrolled: low-income elders who had been receiving their prescription-drug coverage through state Medicaid programs (the "dual eligibles"). These dual eligibles were enrolled in Part D plans by default if they did not choose one on their own.

By now, there is a sizable literature in economics and health services research documenting the program's details and providing descriptive statistics on coverage. A number of economic studies have examined the take-up of Part D benefits, (Heiss, McFadden, and Winter, 2006; Levy and Weir, 2008), plan choice (Lucarelli and Simon, 2009; Abaluck and Gruber, 2011); and the extent Part D crowded out other private forms of prescription drug coverage (Levy and Weir, 2008; Engelhardt and Gruber, 2011). The consensus is that the Part D expansion raised prescription drug insurance coverage among the elderly by about 10 percentage 
points, substantially decreasing the share of the elderly without coverage. As of October, 2010, only 4.7 million, or 10\% of, Medicare beneficiaries had no coverage (Kaiser, 2011).

In order to incorporate the temporal variation in coverage in the framework above, panel data are drawn from the 2005 and 2007 Prescription Drug Study (PDS). The PDS is administered as a supplement to the Health and Retirement Study (HRS), a large nationally representative longitudinal survey of Americans aged 50 and older. The core HRS surveys are administered either in person (CAPI) or by telephone (CATI) every two years in even years, and gather detailed information on demographics, income, employment, health, health insurance, and other topics relevant to the demography and economics of aging.

The PDS is an off-year supplemental mail survey commenced in 2005 and administered in odd years to roughly half (randomly chosen) of HRS respondents who would be 65 and older in 2006 when Part D was implemented. ${ }^{6}$ Unfortunately, the PDS was not administered to those under 65, who would have been a natural comparison group with which to assess the impact of the adoption of Part D. This means that the PDS only measures time variation in coverage, not age-by-time variation. ${ }^{7}$ It was designed to gather information on prescription drug insurance and utilization that would be too time-consuming to gather in a CAPI/CATI interview, and was implemented specifically to provide pre- and post-data on Medicare Part D.

The PDS has two parts. The first part is a questionnaire that asks the individual generally about prescription drug insurance coverage and utilization. This included specific sources of coverage: respondent's or spouse's current or former employer or union; private market purchase

\footnotetext{
${ }^{6}$ That is, those administered the PDS were drawn from years of birth 1941 and earlier. The other half of HRS respondents was administered the Consumption and Activities Mail Survey (CAMS).

${ }^{7}$ Engelhardt and Gruber (2011) develop an instrumental variable (IV) strategy based on age-by-time variation in eligibility for Part D (i.e., above vs. below age 65, before vs. after 2006) to identify the impact of Part D on coverage, drug expenditure, and crowd-out, using pooled cross-sections from the Medical Expenditure Panel Survey (MEPS). This type of approach cannot be implemented in the PDS, for lack of data on those under 65. Despite the name of the survey, the MEPS panel data are not long enough to identify well changes from Part D with panel-data methods.
} 
(e.g., Medigap, prior to Part D); Veteran’s Administration; Medicaid, Medicare HMO or Medicare Advantage; State Pharmacy Assistance Program; Medicare Part D (in 2007); or other source. It included out-of pocket expenditure ("How much do you typically spend of your own money for a one-month supply of your regular drugs?”) and utilization (“Have you used prescription drugs in the last year?”; "How many different prescription drugs did you use in the last month?”; “Of those prescription drugs, how many are ones you take on a regular basis, for example, every day or every week?”). In addition, there are questions on non-adherence commonly used in other studies: "In the past year, how often did you not fill a new prescription because of cost?" (never, 1-2 times, 3-4 times, more than 4 times); “In the past year, how often did you stop taking a prescription medication because of cost?" (never, 1-2 times, 3-4 times, more than 4 times); "In the past year, how often did you skip doses of a prescription medication in order to save money?” (never, 1-2 times, 3-4 times, more than 4 times).

The second part is a medication roster, for which the individual was asked to transcribe information from the labels of the ten most important prescriptions. This information included the drug name (e.g., Ciprofloxacin), the brand or trade name (Cipro) if any, the dosage (500 mg), the date filled (10/18/2005), and the dosage instructions (Take 1 capsule 3 times a day until finished). ${ }^{8}$ In addition, the respondent was asked additional questions about each medicine: "How long have you been taking this medication?”; "How much did you pay the last time you filled the prescription?”; as well as assessments about the medication concerning expense ("It is too expensive” - strongly agree, agree, neutral, disagree, strongly disagree), importance to health (“This medication is very important for my health” - strongly agree, agree, neutral, disagree, strongly disagree), and side effects ("It often gives me unpleasant side effects” - strongly agree,

\footnotetext{
${ }^{8}$ For those taking more than 10 medications, the individual was asked to list just the drug name for any medication beyond the tenth.
} 
agree, neutral, disagree, strongly disagree), as well as non-adherence due to cost and side effects ("In the last year, have you ever missed a dose of this medication or delayed or not filled a prescription for it?”). In the empirical analysis, these data are used to form a drug-level panel dataset to examine the impact of insurance coverage on utilization and non-adherence at a far finer level than in previous studies.

Therefore, the PDS provides fairly comprehensive information at the individual and drug level for the same individuals, both before and after the implementation of Part D. The analysis sample is a strongly balanced panel of 4,536 person-year observations on 2,268 individuals 65 and older. Columns 1 and 2 of Table 1 show sample means for the variables used in the empirical work for 2005 and 2007, respectively, for the individuals in the analysis sample. For comparison, columns 3-5 show the means for the same variables for all HRS individuals 65 and older for 2004, 2006, and 2008 from the HRS core survey data. Along many dimensions, the analysis and full samples are broadly comparable, with some exceptions. The rate of prescription drug coverage appears to be somewhat higher prior to 2006 in the analysis sample, with associated somewhat higher utilization and lower out-of-pocket expenditures. Analysis sample members are more likely to be married as well.

\section{Part III: Insurance Coverage Results}

The empirical analysis starts with Table 2, which examines how prescription drug insurance coverage changed between 2005 and 2007 with the expansion of Part D. This is an important first step for two reasons. First, the table illustrates the temporal change in coverage that will be central to identification in the fixed-effect estimation in the subsequent tables. Second, it allows for a comparison of estimates from the PDS, which is a newly available data 
source (the 2007 wave was released in March, 2011), with estimates from other data sources. In particular, the PDS ought to be able to replicate responses found in other data.

With this in mind, column 1 of Table 2 presents estimates from the following basic specification:

$$
D_{i t}^{\text {AnyCoverage }}=\omega+\phi D_{i t}^{2007}+\zeta \kappa_{i t}+v_{i t} .
$$

The primary explanatory variable is $D^{2007}$, which takes on a value of one if the sample year was in 2007, after Part D was implemented. The vector $\boldsymbol{\kappa}$ contains control variables for whether the individual was married, age, and sets of dummy variables for household income quintiles and Census division of residence, respectively; $v$ is a disturbance term. ${ }^{9}$ The focal explanatory variable is $D^{\text {AnyCoverage }}$, which takes on a value of one if the individual had prescription drug coverage from any source and zero otherwise. Those sources in the PDS include respondent's or spouse's current or former employer or union, private market purchase, Veteran’s Administration, Medicaid, Medicare HMO or Medicare Advantage, State Pharmacy Assistance Program, Medicare Part D (in 2007), or other source. In (3), $\phi$ measures the extent to which any coverage rose with the implementation of Part D (conditional on the control variables in $\mathbf{\kappa}$ ). The OLS linear probability estimate in column 1 shows that such coverage rose by 10.9 percentage points. Because the sample includes person-year observations on the same individuals, the robust standard errors are clustered by individual (and shown in parentheses). This estimate of the change in coverage is very similar to what other studies in the literature have found.

${ }^{9}$ Other standard controls, such as race/ethnicity, veteran status, education, etc., are time-invariant, and the parameters on which cannot be identified with the fixed-effect estimators used in the analysis. So, these variables are not included as controls. 
Column 2 shows the related estimate from the same specification, but with the dependent variable, $D^{\text {Publiccoverage }}$, which takes on a value of one if the individual had prescription-drug coverage from a public source and zero otherwise. Following Engelhardt and Gruber (2011), "public" sources are defined as Medicaid, Medicare HMO, Medicare Advantage, State Pharmacy Assistance Program, or Medicare Part D. In column 2, public coverage rose by 35.5 percentage points across the same years. The quotient of the estimates in columns 1 and 2 , suggests that for every 100 individuals gaining public coverage between 2005 and 2007, only roughly 31 gained any coverage (i.e., 0.109/0.335=0.307), implying the Part D crowded out other coverage by $69 \%$. A direct measure of crowd-out is shown in column 3 for the following specification:

$$
D_{i t}^{\text {AnyCoverage }}=\alpha+\beta D_{i t}^{\text {PublicCoverage }}+\boldsymbol{\psi} \boldsymbol{\kappa}_{i t}+\varepsilon_{i t} \text {, }
$$

Where $\beta$ measures the extent to which public coverage raises any coverage, and, therefore, $1-\beta$ measures crowd-out. The fixed-effect estimate shown in the bottom row of the table is $\hat{\beta}=0.27$ and indicates $73 \%$ crowd-out. This is very similar to the instrumental variable crowdout estimates of Engelhardt and Gruber (2011), based on data from the MEPS. They found 75\% crowd-out. This gives some confidence that PDS can capture behavior found in other studies on Medicare Part D and prescription drugs.

A key assumption for identification under the fixed-effect framework is that unobserved heterogeneity is time-invariant (in levels). In particular, those who switch or obtain coverage are not systematically different from those who do not in how their demand for prescription medication evolves over time. Obviously, with only two waves of PDS data, this assumption cannot be tested directly. Instead, the bottom row of Table 2 provides a partial check on this by including in $\boldsymbol{\kappa}$ two variables measured in the PDS that indicate intentions to switch coverage. The first is a dummy variable that takes on a value of one if in 2005 the individual stated he/she 
was very likely to enroll in Part D, and zero otherwise. This "enrollment likelihood" question was asked to all individuals in 2005, even those with private prescription drug coverage. The second is a dummy variable that takes on a value of one if the individual indicated he/she had considered in the last year switching prescription drug plans, and zero otherwise. This question was asked to all individuals in 2007. Controlling for these switching variables, the estimate of is $\beta$ similar. Though not airtight, this lends at least some credibility to the central identification assumption.

\section{Part VI: Utilization Results}

Changes in drug utilization from gaining coverage can be thought of along four dimensions. There are potential extensive margin changes in the share of the elderly using any prescription drugs. However, these will be expected to be small, given that almost $92 \%$ of the elderly in 2005 used prescription drugs. In addition, there are potential intensive margin responses: a) holding the number and composition of drugs taken constant, more doses can be $\operatorname{taken}^{10}$; b) holding the number of drugs constant, the composition could change, driven by substitution based on price (e.g., within drug, from brand toward generic, or within therapeutic class, across drugs that are therapeutically similar) or quality (e.g., toward drugs with fewer side effects); c) the number of drugs taken could change. It should be emphasized that for each of these four dimensions, gaining coverage could reduce cost-related non-adherence.

Table 3 shows estimates of the impact of prescription drug coverage on drug utilization. These estimates are simply the net impact of prescription drug coverage on utilization, and are based on the specification in (1). The dependent variable in column 1 of the table is an indicator

\footnotetext{
${ }^{10}$ Except for reasons related to cost, it would seem this would be an unlikely channel for response, as it would be presumed that a physician would prescribe the clinically appropriate dosage for the individual's medical condition and characteristics.
} 
for whether the individual used any prescription drugs in the last year and measures the extensive margin. It is drawn from the questionnaire portion of the PDS. The dependent variables in columns 2 and 3 measure the intensive margin c), the number of drugs used in the last month, in total and on a regular basis (every or every week), respectively. They are drawn from the questionnaire portion of the PDS. The dependent variable in column 4 also measures the intensive margin c), but is the number of prescription drugs from the medication roster. For those with more than 10 drugs, this measure is right-censored.

The fixed-effect estimate of $\theta$ shown in column 1 indicates a 3.7 percentage point increase in utilization on the extensive margin associated with insurance coverage. This is a relatively small effect given that almost $82 \%$ of the uninsured used prescription drugs prior to the Part D expansion (in 2005), as shown in the bottom row of the table. Columns 2 and 3 show the estimates for the impact of coverage on the number of drugs taken, both in total and on a regular basis, in the last month. ${ }^{11}$ Here, $\hat{\theta}=0.4$, which relative to the sample mean for the uninsured in 2005 suggests that coverage increases the number of drugs taken by about $13 \%$. Column 4 shows the random-effects censored regression estimate for the number of prescription drugs listed on the medication roster. Based on this measure, utilization rose by $17 \%$.

\section{Part V: Results on Non-Adherence}

To attempt to disentangle how much of the changes in utilization from gaining coverage are related to reductions in financial constraints, Table 4 shows estimates from the following econometric model:

\footnotetext{
${ }^{11}$ Estimates based on count-data models yielded similar results to those shown in this and subsequent tables. The lack of substantial censoring at zero and the relatively large number of count outcomes are two important reasons why the count-data and linear least squares estimators produce similar results in this application (Cameron and Trivedi, 1986).
} 


$$
D_{i t}^{C R N}=\mu+\rho D_{i t}^{\text {AnyCoverage }}+\xi_{\boldsymbol{\kappa}_{i t}}+e_{i t},
$$

where $D^{C R N}$ is a dependent variable that is one of three general measures of cost-related nonadherence (CRN) typically used in the literature and taken from the PDS questionnaire: whether any unfilled prescriptions in the last year, whether stopped taking a medication due to cost in the last year, and whether skipped doses to save money in the last year. The bottom row of the table shows that across measures, almost $20 \%$ of the uninsured experienced cost-related nonadherence in 2005. The fixed-effect estimates in the second row indicate that coverage reduces cost-related non-adherence fairly substantially, by 4-7 percentage points. Relative to the sample mean in the bottom row these represent $20-35 \%$ declines in the incidence of cost-related nonadherence.

Table 5 exploits the data from the medication roster and moves to a person-year-drug level model isomorphic to (5):

$$
D_{i j t}^{C R N}=\mu+\rho D_{i t}^{\text {AnyCoverage }}+\xi \boldsymbol{\kappa}_{i t}+e_{i j t},
$$

in which $j$ indexes the drug. The key to this analysis is that the individual was asked a battery of questions about each drug separately listed on the roster. There are two questions related to nonadherence, one for cost and the other for side effects. Each is based on the lead-in: "In the last year, have you ever missed a dose of this medication or delayed or not filled a prescription for it?” There are 16,586 person-drug-year observations in the prescribed medication sample. Column 1, row 1 of the table shows that $11.7 \%$ of the drugs taken by the uninsured in 2005 had associated episodes of cost-related non-adherence. This is a relatively low frequency, but only reflects drugs taken. It may be that the most elastic cost margin is whether to take the drug at all. This statistic also sheds little light on the marginal health benefit of the non-adhered drugs. 
Column 3, row 1 of the table shows that 3.1\% of the drugs taken by the uninsured in 2005 had associated episodes of side-effect-related non-adherence.

Columns 2 and 4 show the impact of gaining coverage on these two forms of nonadherence, respectively, with robust standard errors clustered by individual shown in parentheses. There is a 5.6 percentage point reduction in cost-related non-adherence associated with prescription drug coverage. On a base of 11.7 percentage points for the uninsured in 2005, this represents a $48 \%$ reduction in the incidence of cost-related non-adherence, a statistically significant and economically substantial effect. There is essentially no corresponding reduction in side-effect-related non-adherence.

The remaining two rows of the table provide separate estimates by the "vintage" of the drug. Here vintage refers to the length of time the individual reports having taken the drug. There are two groups. "New" drugs are drugs that have been taken for two years or less. For the 2007 wave of the PDS, this covers all drugs prescribed in 2006 and 2007, after the implementation of Part D; for the 2005 wave, this covers all drugs prescribed in 2004 and $2005{ }^{12}$ Hence, "new” drugs will be those prescribed after the increase in coverage associated with the Part D expansion. This will include drugs in intensive margins b) and c) described above. Conversely, "old” drugs are those that the individual reports having taken for more than 2 years. Approximately $40 \%$ of drugs are "new" and $60 \%$ are "old"; these shares are not affected by insurance coverage (estimates not shown). Interestingly, the impact of gaining coverage on cost-related non-adherence resides almost wholly among "old” drugs. Therefore,

\footnotetext{
${ }^{12}$ Depending on the date the PDS was filled out, this two-year window could spill back into part of 2005 for those reporting in the 2007 wave, and back into 2003 for those reporting in the 2005 wave. Finer coding to align with calendar years exactly is not possible as the responses to these questions had pre-set categories that determine the look-back periods.
} 
the drugs prescribed on the margin after coverage expanded from Part D were not differentially better adhered to because of cost (sharing).

\section{Part VI: Other Results}

Table 6 shows estimates from the person-drug-year panel for a model isomorphic to (6):

$$
D_{i j t}^{\text {Assessment }}=\mu+\rho D_{i t}^{\text {AnyCoverage }}+\xi_{\boldsymbol{\kappa}_{i t}}+e_{i j t},
$$

in which the dependent variable is a dummy variable that takes on a value of one if there was an affirmative assessment of the drug by the individual along, respectively, these dimensions: importance to health (“This medication is very important for my health” - strongly agree, agree, neutral, disagree, strongly disagree), side effects ("It often gives me unpleasant side effects” strongly agree, agree, neutral, disagree, strongly disagree); and cost ("It is too expensive” strongly agree, agree, neutral, disagree, strongly disagree). An affirmative assessment is defined as an answer of strongly agree or agree.

Column 1, row 1 of the table shows that $91 \%$ of drugs taken by the uninsured in 2005 were considered very important to health. However, new drugs (row 2) were less likely than old drugs (row 3) to be viewed as very important to health, suggesting lower benefits from newer prescriptions. Column 2, row 1 shows the estimate of $\rho$ in (7), with robust standard errors clustered on the individual in parentheses. It is economically small and statistically insignificant, suggesting that gaining coverage is not associated with a greater incidence of medications that are central to health. This is equally true for new and old drugs. Similarly, there are no effects of gaining coverage on assessments concerning unpleasant side effects, a direct health impact (columns 3 and 4). Overall, the results in results in columns 1-4 suggest little link between prescription drug coverage and self-assessments of the importance of drugs taken to health. 


\section{Part VII: Discussion and Caveats}

In summary, the empirical analysis indicates gaining prescription drug coverage results in an estimated $15 \%$ increase in drug utilization, as measured by the number of prescription drugs taken. It does not appear that all of this increase can be explained easily by the loosening of financial constraints for two reasons. First, the large estimated reductions in cost-related nonadherence (20-50\%) apply to a small slice of all drugs (11\%). Second, this effect is concentrated on “old” drugs. Gaining coverage does not seem to differentially impact non-adherence for new prescriptions.

There are a number of caveats to these findings. First, these results are substantially smaller than those implied by other reduced-form studies of the impact of Part D eligibility on drug utilization and cost-related non-adherence. Reconciling the disparate findings is probably an important part of future research. Second, what explains the remaining $88 \%$ of the increase in utilization from gaining coverage remains an important and unanswered question. In particular, this paper does not attempt to determine how much of the increase in utilization is due to welfare-diminishing moral hazard.

The estimation of the extent of moral hazard is complicated in this case. First, moral hazard is the substitution effect from the reduction in price (e.g., per prescription) to the individual from the insurance. The estimates in the paper are clearly picking up uncompensated responses that are a mix of income effects from Part D (Engelhardt and Gruber, 2011) and substitution effects. Moran and Simon (2006) estimated an income elasticity of demand for prescription drugs of 1.3, suggesting there might be a substantial wedge between the uncompensated responses estimated here and the compensated responses associated with deadweight loss from moral hazard. In general, it is not possible to disentangle the substitution 
and income effects without the use of a structural model, something of great interest, but beyond the scope of the current analysis. Second, to the extent price exceeds marginal cost for some pharmaceuticals, increased utilization may be welfare improving (Frick and Chernew, 2009). Third, to the extent there is adverse selection in the market for prescription drug insurance, increases in drug utilization from gaining coverage will represent a combination of adverse selection, because sicker individuals who gain coverage on the margin will on average take more prescriptions, and moral hazard. Finally, the welfare implications of changes in drug utilization have to be considered in the context of broader measures of non-prescription drug medical utilization, to the extent drug and non-drug care are substitutes or complements. Better identifying and estimating the welfare implications of prescription drug utilization is clearly an important avenue for future research. 


\section{References}

Abaluck, Jason and Jonathan Gruber (2011). "Choice Inconsistencies Among the Elderly: Evidence from Plan Choice in the Medicare Part D Program,” American Economic Review 101:4, 1180-1210.

Cameron, A. Colin, and Pravin K. Trivedi (1986). "Econometric Models Based on Count Data: Comparisons and Applications of Some Estimators and Tests,” Journal of Applied Econometrics, 1, 29-53.

Engelhardt, Gary V., and Jonathan Gruber (2011). "Medicare Part D and the Financial Protection of the Elderly,” American Economic Journal: Economic Policy 3:4, 127.

Frick, Kevin D., and Michael E. Chernew (2009). "Beneficial Moral Hazard and the Theory of the Second Best,” Inquiry 46, 229-240.

Heisler, Michele, Kenneth M. Langa, Elizabeth L. Eby, A. Mark Fendrick, Mohammed U. Kabeto, and John D. Piette (2004). "The Health Effects of Restricting Prescription Medication Use Because of Cost,” Medical Care, 42, 626-634.

Heiss, F., D. McFadden, and J. Winter (2006). "Who Failed to Enroll in Medicare Part D, and Why? Early Results” Health Affairs, 25: 344-354.

Kennedy, James J., Matthew Maciejewski, Darren Liu, and Elizabeth Blodgett (2011). "Cost-Related Nonadherence in the Medicare Program: Impact of Part D," Medical Care 49:5, 522-526.

Ketcham, Jonathan and Kosali Simon (2008). “Medicare Part D’s Effects on Elderly Drug Costs and Utilization,” American Journal of Managed Care, November, 1422.

Khan, Nasreen, and Robert Kaestner (2009). "Effect of Prescription Drug Coverage on the Elderly's Use of Prescription Drugs,” Inquiry, 46, 33-45.

Levy, Helen, and David R. Weir (2010). "Take-Up of Medicare Part D: Evidence from the Health and Retirement Study.” Journal of Gerontology: Social Sciences 65B(4): 492 501.

Lichtenberg, Frank and Shawn Sun (2007). "The Impact of Medicare Part D on Prescription Drug Use by the Elderly,” Health Affairs, 26, 1735-1744.

Lillard, Lee A., Jeannette Rogowski, and Roger Kington (1999). “Insurance Coverage for Prescription Drugs: Effects on Use and Expenditures in the Medicare Population,” Medical Care 37:9, 926-936. 
Lucarelli, Claudo, Jeffrey Prince, and Kosali Simon (2009). "Measuring Welfare and the Effects of Regulation in a Government-Created Market: The Case of Medicare Part D,” NBER Working Paper No. 14296.

Madden, Jeanne M., Amy J. Graves, Fang Zhang, Alyce S. Adams, Becky A. Breisbacher, Dennis Ross-Degnan, Jeryy H. Gurwitz, Marsha Pierre-Jacques, Dana Gelb Safran, Greald S. Adler, and Stephen B. Soumerai (2008). "Cost-Related Medication Nonadherence and Spending on Basic Needs Following Implementation of Medicare Part D,” Journal of the American Medical Association, 299 (16), 19221928.

Moran, John D., and Kosali Simon (2006). "Income and the Use of Prescription Drugs by the Elderly: Evidence from the Notch Cohorts," Journal of Human Resources, 41, 411-432.

Pauly, Mark (2004). “Medicare Drug Coverage and Moral Hazard,” Health Affairs, 23, 113-122.

Sokol, Michael C., Kimberly A. McGuigan, Robert R. Verbrugge, and Robert S. Epstein (2005). "Impact of Medication Adherence on Hospitalization Risk and Healthcare Cost,” Medical Care 43:6, 521-530.

Yang, Z., D.B. Gilleskie, and E.C. Norton (2004). "Prescription Drugs, Medical Care, and Health Outcomes: A Model of Elderly Health Dynamics,” NBER Working Paper No. 10964.

Yin, W. et al. (2008). "The Effect of the Medicare Part D Prescription Drug Benefit on Drug Utilization and Expenditures,” Annals of Internal Medicine, 148, 169-177.

Zhang, Yuting, Julie M. Donohue, Judith R. Lave, Gerald O’Donnell, and Joseph P. Newhouse (2009). "The Effect of Medicare Part D on Drug and Medical Spending,” New England Journal of Medicine, 361, 52-61.

Zhang, Yuting, Judith R. Lave, Julie M. Donohue, Michael A. Fischer, Michael E. Chernew, and Joseph P. Newhouse (2010). "The Impact of Medicare Part D on Medication Adherence Among Older Adults Enrolled in Medicare-Advantage Products,” Medical Care, 48:5, 409-417.

Zivin, Kara, Jeanne M. Madden, Amy J. Graves, Fang Zhang, and Stephen Soumerai (2009). "Cost-Related Medication Nonadherence Among Beneficiaries with Depression Following Medicare Part D," American Journal of Geriatric Psychiatry 17:12, 1068-1076. 
Table 1. Sample Means for Selected Variables, by Year for the Analysis and Full HRS Samples

\begin{tabular}{|c|c|c|c|c|c|}
\hline \multirow{3}{*}{$\begin{array}{l}\text { Sample/Year: } \\
\text { Variable }\end{array}$} & \multirow{2}{*}{\multicolumn{2}{|c|}{$\begin{array}{l}(1) \quad(2) \\
\text { Analysis Sample }\end{array}$}} & \multirow{2}{*}{\multicolumn{2}{|c|}{$\begin{array}{l}\text { (3) (4) } \\
\text { All Elderly }\end{array}$}} & \multirow{3}{*}{$\begin{array}{l}5) \\
2008 \\
\end{array}$} \\
\hline & & & & & \\
\hline & \multicolumn{2}{|c|}{ Analysis sample } & 2004 & \multirow{2}{*}{$\frac{2006}{0.937}$} & \\
\hline Dummy if Covered by Any Prescription Drug Insurance & 0.835 & 0.942 & 0.785 & & 0.958 \\
\hline Dummy if Covered by Public Prescription Drug Insurance & 0.206 & 0.568 & 0.240 & 0.493 & 0.573 \\
\hline Dummy if Used Any Prescription Drugs in the Last Year & 0.915 & 0.941 & 0.862 & 0.884 & 0.900 \\
\hline Total Number of Prescription Drugs in Last Month & 4.078 & 4.617 & --- & --- & --- \\
\hline Number of Prescription Drugs Used Regularly in Last Month & 3.844 & 4.355 & --- & --- & --- \\
\hline Number of Prescription Drugs from Medication Roster & 3.674 & 3.921 & --- & --- & --- \\
\hline Dummy if Any Unfilled Prescriptions in the Last Year & 0.120 & 0.098 & 0.077 & 0.076 & 0.062 \\
\hline Dummy if Stopped Taking a Prescription Medication in the Last Year & 0.096 & 0.072 & --- & --- & --- \\
\hline Dummy if Skipped Doses to Save Money in the Last Year & 0.114 & 0.085 & --- & --- & --- \\
\hline Dummy if Any Monthly Out-of-Pocket Prescription Drug Expenditure & 0.890 & 0.895 & --- & --- & --- \\
\hline Monthly Out-of-Pocket Prescription Drug Expenditure (in 2010 \$) & 83 & 64 & 113 & 62 & 52 \\
\hline Dummy Married & 0.688 & 0.654 & 0.613 & 0.597 & 0.580 \\
\hline Age (in months) & 858 & 881 & 879 & 895 & 911 \\
\hline Annual Household Income (in 2010 \$) & 59,816 & 54,403 & 57,019 & 54,653 & 60,121 \\
\hline Census Division - New England & 0.043 & 0.043 & 0.042 & 0.042 & 0.041 \\
\hline Census Division - Mid-Atlantic & 0.106 & 0.104 & 0.114 & 0.110 & 0.111 \\
\hline Census Division - East North Central & 0.174 & 0.171 & 0.172 & 0.171 & 0.169 \\
\hline Census Division - West North Central & 0.108 & 0.108 & 0.095 & 0.098 & 0.098 \\
\hline Census Division - South Atlantic & 0.241 & 0.245 & 0.239 & 0.237 & 0.240 \\
\hline Census Division - East South Central & 0.069 & 0.068 & 0.066 & 0.070 & 0.069 \\
\hline Census Division - West South Central & 0.099 & 0.099 & 0.102 & 0.105 & 0.103 \\
\hline Census Division - Mountain & 0.043 & 0.044 & 0.054 & 0.054 & 0.056 \\
\hline Census Division - Pacific & 0.118 & 0.118 & 0.116 & 0.114 & 0.113 \\
\hline
\end{tabular}

Note: Each cell shows the sample mean for the variable in the row heading and the sample in the column heading. The analysis sample consists of a strongly balanced panel of 4416 person-year observations on 2208 persons 65 and older drawn from the 2004 and 2006 waves of the HRS, who responded to the 2005 and 2007 HRS Prescription Drug Survey. To facilitate comparisons, the samples in columns 3-5 represent all elderly in the HRS for that year with the same birth years and months as individuals in the analysis sample. 
Table 2. OLS and Fixed-Effect Estimates of Changes in Prescription Drug Coverage, Robust Standard Errors in Parentheses

\begin{tabular}{|c|c|c|c|}
\hline Explanatory Variable & $\begin{array}{l}(1) \\
\text { Dummy if } \\
\text { Covered by } \\
\text { Any } \\
\text { Prescription } \\
\text { Drug } \\
\text { Insurance } \\
\end{array}$ & $\begin{array}{l}(2) \\
\text { Dummy if } \\
\text { Covered by } \\
\text { Public } \\
\text { Prescription } \\
\text { Drug } \\
\text { Insurance } \\
\end{array}$ & $\begin{array}{l}\text { (3) } \\
\text { Dummy if } \\
\text { Covered by } \\
\text { Any } \\
\text { Prescription } \\
\text { Drug } \\
\text { Insurance } \\
\end{array}$ \\
\hline \multicolumn{4}{|l|}{ Linear Probability Model Estimates } \\
\hline Dummy if 2007 & $\begin{array}{l}0.109 \\
(0.008)\end{array}$ & $\begin{array}{l}0.355 \\
(0.012)\end{array}$ & --- \\
\hline Dummy if Covered by Public Prescription Drug Insurance & --- & --- & $\begin{array}{l}0.174 \\
(0.009)\end{array}$ \\
\hline \multicolumn{4}{|l|}{ Fixed-Effects Estimates } \\
\hline Dummy if Covered by Public Prescription Drug Insurance & --- & --- & $\begin{array}{l}0.270 \\
(0.015)\end{array}$ \\
\hline $\begin{array}{l}\text { Fixed-Effects Estimates with Controls for Switching Cover } \\
\text { Dummy if Covered by Public Prescription Drug Insurance }\end{array}$ & & & $\begin{array}{l}0.258 \\
(0.015)\end{array}$ \\
\hline
\end{tabular}

Note: Each cell in the first two rows of the table represents the parameter estimate of the impact of the explanatory variable in the first column on the outcomes shown in the other column headings. The sample consists of a strongly balanced panel of persons 65 and older drawn from the 2004 and 2006 waves of the HRS, who responded to the 2005 and 2007 HRS Prescription Drug Survey. All specifications control for marital status, age, Census division, and income quintile. Robust standard errors clustered at the individual level are shown in parentheses. 
Table 3. OLS and Fixed-Effect Estimates of the Impact of Prescription Drug Coverage on Various Measures of Utilization, Robust Standard Errors in Parentheses

(1) (2) (3) (4)

Questionnaire

Source:

Explanatory Variable

OLS Estimates

Dummy if Covered by Prescription Drug Insurance

0.175

$(0.021)$

1.742

$(0.134)$

1.664

$(0.128)$

Used Any

Prescription

Drugs in the

Number of

Drugs in the Basis in the

Last Month
Number of

Drugs

Taken on a

Medication

Roster

Last Month

Number of Drugs

Censored Regression Estimates

Dummy if Covered by Prescription Drug Insurance

$(0.121)$

\section{Fixed-Effects Estimates}

Dummy if Covered by Prescription Drug Insurance

Random-Effects Censored Regression Estimates

Dummy if Covered by Prescription Drug Insurance

2005 Sample Mean for the Uninsured

0.816

3.053

2.877

3.348

Note: Each cell in the first two rows of the table represents the parameter estimate of the impact of prescription drug insurance coverage on the utilization outcomes shown in the column headings. The sample consists of a strongly balanced panel of persons 65 and older drawn from the 2004 and 2006 waves of the HRS, who responded to the 2005 and 2007 HRS Prescription Drug Survey. All specifications control for marital status, age, Census division, and income quintile. Robust standard errors clustered at the individual level are shown in parentheses. 
Table 4. OLS and Fixed-Effect Estimates of the Impact of Prescription Drug Coverage on Cost-Related Non-Adherence, Standard Errors in Parentheses

\begin{tabular}{|c|c|c|c|}
\hline Explanatory Variable & $\begin{array}{l}\text { Any Unfilled } \\
\text { Prescriptions in } \\
\text { the Last Year }\end{array}$ & $\begin{array}{l}\text { (2) } \\
\text { Stop Taking a } \\
\text { Prescription } \\
\text { Medication } \\
\text { Due to Cost in } \\
\text { the Last Year } \\
\end{array}$ & $\begin{array}{l}\text { Skipped Doses } \\
\text { to Save Money } \\
\text { in the Last Year }\end{array}$ \\
\hline \multicolumn{4}{|l|}{ Linear Probability Model Estimates } \\
\hline Dummy if Covered by Prescription Drug Insurance & $\begin{array}{l}-0.083 \\
(0.022)\end{array}$ & $\begin{array}{l}-0.091 \\
(0.021)\end{array}$ & $\begin{array}{l}-0.076 \\
(0.022)\end{array}$ \\
\hline \multicolumn{4}{|l|}{ Fixed-Effects Estimates } \\
\hline Dummy if Covered by Prescription Drug Insurance & $\begin{array}{l}-0.072 \\
(0.029)\end{array}$ & $\begin{array}{l}-0.036 \\
(0.027)\end{array}$ & $\begin{array}{l}-0.046 \\
(0.027)\end{array}$ \\
\hline 2005 Sample Mean for the Uninsured & 0.198 & 0.190 & 0.194 \\
\hline
\end{tabular}

Note: Each cell in the first two rows of the table represents the parameter estimate of the impact of prescription drug insurance coverage on the utilization outcomes shown in the column headings. The sample consists of a strongly balanced panel of persons 65 and older drawn from the 2004 and 2006 waves of the HRS, who responded to the 2005 and 2007 HRS Prescription Drug Survey and utilized prescription drugs. Thus, they are a subsample of those in Table 3 . All specifications control for marital status, age, Census division, and income quintile. Robust standard errors clustered at the individual level are shown in parentheses. 
Table 5. Fixed Effect Estimates of the Impact of Prescription Drug Coverage on the Incidence of Non-Adherence due to Cost and Side Effects, by Drug Vintage, Robust Standard Errors in Parentheses

\begin{tabular}{|c|c|c|c|c|}
\hline \multirow[b]{2}{*}{ Drug Vintage } & \multicolumn{2}{|c|}{$\begin{array}{l}\text { Non-Adherence } \\
\text { Due to Cost }\end{array}$} & \multicolumn{2}{|c|}{$\begin{array}{l}\text { Non-Adherence } \\
\text { Due to Side Effects }\end{array}$} \\
\hline & $\begin{array}{l}\text { Share of } \\
\text { Drugs in } \\
\text { 2005, for the } \\
\text { Uninsured }\end{array}$ & $\begin{array}{l}\text { Estimated } \\
\text { Impact of } \\
\text { Drug } \\
\text { Insurance } \\
\text { Coverage }\end{array}$ & $\begin{array}{l}\text { Share of } \\
\text { Drugs in } \\
\text { 2005, for the } \\
\text { Uninsured }\end{array}$ & $\begin{array}{l}\text { Estimated } \\
\text { Impact of } \\
\text { Drug } \\
\text { Insurance } \\
\text { Coverage }\end{array}$ \\
\hline All & 0.117 & $\begin{array}{l}-0.056 \\
(0.020)\end{array}$ & 0.031 & $\begin{array}{l}-0.002 \\
(0.015)\end{array}$ \\
\hline New & 0.113 & $\begin{array}{l}-0.017 \\
(0.036)\end{array}$ & 0.038 & $\begin{array}{l}0.037 \\
(0.028)\end{array}$ \\
\hline Old & 0.119 & $\begin{array}{l}-0.060 \\
(0.021)\end{array}$ & 0.026 & $\begin{array}{l}0.002 \\
(0.015)\end{array}$ \\
\hline
\end{tabular}

Note: Each cell in the first two rows of the table represents the parameter estimate of the impact of prescription drug insurance coverage on the characteristics of the drugs shown in the column headings. The sample consists of a strongly balanced panel of persons 65 and older drawn from the 2004 and 2006 waves of the HRS, who responded to the 2005 and 2007 HRS Prescription Drug Survey and utilized prescription drugs. Thus, they are a subsample of those in Table 3. All specifications control for marital status, age, Census division, and income quintile. Robust standard errors clustered at the individual level are shown in parentheses. 
Table 6. Fixed-Effect Estimates of the Impact of Prescription Drug Coverage on Assessments of Drugs Concerning Expense, Side Effects, and Importance to Health, by Drug Vintage, Robust Standard Errors in Parentheses

\begin{tabular}{|c|c|c|c|c|c|c|}
\hline \multirow[b]{2}{*}{ Drug Vintage } & \multicolumn{2}{|c|}{$\begin{array}{l}\text { Drug Considered Too } \\
\text { Expensive }\end{array}$} & \multicolumn{2}{|c|}{$\begin{array}{l}\text { Drug Very Important } \\
\text { to Health }\end{array}$} & \multicolumn{2}{|c|}{$\begin{array}{l}\text { Drug with Unpleasant } \\
\text { Side Effects }\end{array}$} \\
\hline & $\begin{array}{l}\text { Share in } \\
2005 \text { for } \\
\text { the } \\
\text { Uninsured }\end{array}$ & $\begin{array}{l}\text { Estimated } \\
\text { Impact of } \\
\text { Drug } \\
\text { Insurance } \\
\text { Coverage }\end{array}$ & $\begin{array}{l}\text { Share in } \\
2005 \text { for } \\
\text { the } \\
\text { Uninsured }\end{array}$ & $\begin{array}{l}\text { Estimated } \\
\text { Impact of } \\
\text { Drug } \\
\text { Insurance } \\
\text { Coverage }\end{array}$ & $\begin{array}{l}\text { Share in } \\
2005 \text { for } \\
\text { the } \\
\text { Uninsured }\end{array}$ & $\begin{array}{l}\text { Estimated } \\
\text { Impact of } \\
\text { Drug } \\
\text { Insurance } \\
\text { Coverage }\end{array}$ \\
\hline All & 0.403 & $\begin{array}{l}-0.139 \\
(0.025)\end{array}$ & 0.911 & $\begin{array}{l}0.012 \\
(0.015)\end{array}$ & 0.052 & $\begin{array}{l}-0.002 \\
(0.012)\end{array}$ \\
\hline New & 0.500 & $\begin{array}{l}-0.197 \\
(0.042)\end{array}$ & 0.879 & $\begin{array}{l}0.034 \\
(0.035)\end{array}$ & 0.080 & $\begin{array}{l}-0.006 \\
(0.029)\end{array}$ \\
\hline Old & 0.346 & $\begin{array}{l}-0.098 \\
(0.030)\end{array}$ & 0.929 & $\begin{array}{l}0.022 \\
(0.017)\end{array}$ & 0.035 & $\begin{array}{l}0.016 \\
(0.012)\end{array}$ \\
\hline
\end{tabular}

Note: Each cell in the first two rows of the table represents the parameter estimate of the impact of prescription drug insurance coverage on the characteristics of the drugs shown in the column headings. The sample consists of a strongly balanced panel of 2,629 persons 65 and older drawn from the 2004 and 2006 waves of the HRS, who responded to the 2005 and 2007 HRS Prescription Drug Survey and utilized prescription drugs. Thus, they are a subsample of those in Table 3. All specifications control for marital status, age, Census division, and income quintile. Robust standard errors clustered at the individual level are shown in parentheses. 


\section{RECENT WORKING PAPERS FROM THE CENTER FOR RETIREMENT RESEARCH AT BOSTON COLLEGE}

Social Security on Auto-Pilot: International Experience with Automatic Stabilizer Mechanisms

Barry Bosworth and R. Kent Weaver, November 2011

The Impact of Unemployment Insurance Extensions on Disability Insurance Application and Allowance Rates

Matthew S. Rutledge, October 2011

Do Couples Self-Insure? The Effect of Informal Care on a Couple's Labor Supply

Norma B. Coe, Meghan Skira, and Courtney Harold Van Houtven, October 2011

How Prepared are State and Local Workers for Retirement?

Alicia H. Munnell, Jean-Pierre Aubry, Josh Hurwitz, and Laura Quinby, October 2011

Social Security Reform and Male Labor Force Participation Around the World Jocelyn E. Finlay and Günther Fink, September 2011

Corporate Pension Plan Investments in Alternative Assets: Determinants and Consequences

Divya Anantharaman, August 2011

Social Security Reform and Male Labor Force Participation Around the World Jocelyn E. Finlay and Günther Fink, June 2011

An In-Depth Look into Intergenerational Flows

Oksana Leukhina and Marika Santoro, May 2011

Who Retires Early?

Henry J. Aaron and Jean Marie Callan, May 2011

The Potential Impact of the Great Recession on Future Retirement Incomes Barbara A. Butrica, Richard W. Johnson, and Karen E. Smith, May 2011

Immigrant Diversity and Social Security: Recent patterns and Future Prospects Melissa M. Favreault and Austin Nichols, May 2011

Why Aren't More Families Buying Life Insurance?

Matthew S. Chambers, Don E. Schlagenhauf, and Eric R. Young, March 2011

Changes in Firm Pension Policy: Trends Away From Traditional Defined Benefit Plans Kandice A. Kapinos, February 2011

All working papers are available on the Center for Retirement Research website (http://crr.bc.edu) and can be requested by e-mail (crr@bc.edu) or phone (617-552-1762). 